\title{
A study of clinical spectrum of tuberculosis in BCG vaccinated children in age group of 2 months to 12 years
}

\author{
Rohit Bhandar ${ }^{1 *}$, Veeresh Ingleshwar ${ }^{2}$ \\ ${ }^{1}$ Associte Professor, Department of Paeditrics, M R Medical College, Kalaburagi, Karnataka, INDIA. \\ Consultant Pediatrician, Veeresh Clinic Wadi, Kalaburagi, Karnataka, INDIA. \\ Email: drrohitmb@yahoo.com
}

Abstract Background: Tuberculosis is a worldwide problem. According to WHO reports, tuberculosis remains a widespread disease in developing countries and even in a number of technically advanced countries resulting in more deaths than all other notifiable diseases. Inspite of the large coverage of BCG, the disease in the BCG immunized population is still a big quantum. Aim and objective: To study the clinical spectrum of tuberculosis in BCG vaccinated children in age group of 2 months to 12 years. Methodology: This prospective study was conducted on Children in the age group from 2 months to 12 years attending the Outpatient Department, admitted in the wards or in the PICU with sysmptoms suggestive of Tuberculous disease. Data was collected with pre tested questionnaire. Data included sociodemographic data, clinical history and clinical examination. Results: The present study shows predominatnt sysmptoms of presentation were Fever $68(65.38 \%)$ and cough 61 (58.65\%). 38(36.53\%) had initial presentation as seizures. One third had weight loss or poor weight gain, Significant lymphadenopathy was observed in $28(26.92 \% 0$ cases and $14(13.46 \%)$ has wheezing.

Key Word: BCG vaccine.

*Address for Correspondence:

Dr. Rohit Bhandar, Associte Professor, Department of Paeditrics, M R Medical College, Kalaburagi, Karnataka, INDIA.

Email: chat suva@yahoo.co.in

Received Date: 09/11/2019 Revised Date: 13/12/2019 Accepted Date: 16/01/2020

DOI: $\underline{\text { https://doi.org/10.26611/10141523 }}$

This work is licensed under a Creative Commons Attribution-NonCommercial 4.0 International License. $($ (c) ) EY-NC

\begin{tabular}{|c|c|}
\hline \multicolumn{2}{|c|}{ Access this article online } \\
\hline Quick Response Code: & \multirow{2}{*}{$\begin{array}{l}\text { Website: } \\
\text { www.medpulse.in }\end{array}$} \\
\hline & \\
\hline & $\begin{array}{c}\text { Accessed Date: } \\
04 \text { September } 2020\end{array}$ \\
\hline & \\
\hline
\end{tabular}

\section{INTRODUCTION}

Globally it has been estimated that 1.9 billion people $(1 / 3$ of world's population) are infected and 5000 people die of TB Globally each day. ${ }^{1}$ Out of which $95 \%$ are in the developing world. About 3 million cases die every year with an addition of 4-5 million new cases every year. ${ }^{2}$ The majority of infected individuals live in South East Asian regions. More than $90 \%$ of deaths are reported to occur in low-income countries.

In India 1.8 million new cases annually accounting for one fifth of new cases two of every 5 persons ( $>400$ million) in general population have latent tuberculosis. ${ }^{3}$

Tuberculosis long known to be a major cause of morbidity and mortality throughout the world has for the several decades been a neglected disease in both industrialized and developing countries specially in children because of the difficulty of confirming the diagnosis. The Global burden of childhood Tuberculosis in the world is unclear. Another important reason is that children do not make a significant contribution to the spread of tuberculosis. ${ }^{4}$

The actual global disease burden of childhood TB is not known, but it has been assumed that $10 \%$ of the actual total TB caseload is found amongst children. Global estimate of 1.5 million new cases and 130,000 deaths due to TB per year amongst children is reported. However these figures appear to be an underestimate of the size of the problem. 
Children can present with TB at any age, but the majority of cases present between 1 and 4 years. Disease usually develops within one year of infection. In younger individuals the progression to disease is earlier and is more disseminated. Pulmonary tuberculosis (PTB) is usually smear negative. PTB to extra-pulmonary TB (EPTB) ratio is usually around $3: 14$. In infants, the time span between infection and disease can be as little as 6-8 weeks.

Untreated adults pass the disease on to $43 \%$ of children under one and to $16 \%$ of children from 11-15 years old. Only $5-10 \%$ of adults in similar contact would contract the disease. Scientific data on the burden of all forms of TB amongst children in India are not available. Most surveys conducted have focused on pulmonary TB and no significant population based studies on extra pulmonary TB are available. Pulmonary TB is primarily and adult disease and it has been estimated that in 0-19 year old population PTB is only $7 \%{ }^{5}$

After the implementation of expanded and universal immunization programmes in India, there is substantial improvement in BCG vaccination coverage reaching up to $90 \%$ in urban areas. ${ }^{6}$ In spite of this improved vaccination coverage and timely revised treatment protocols the disease is still rampant, and multidrug resistant strains tuberculosis (MDRTB) have under debate. ${ }^{7,8}$ HIV positivity amongst patients with tuberculosis attending tuberculosis centers is considerably higher than in the general populations. ${ }^{9}$

The highlighted fact is that tuberculosis is less a disease of the individual and more strikingly a disease of the family and of the community. This is even more the case with tuberculosis in children. However, the ultimate goal is to protect children from infection, allow the emergence of a whole generation free form infection and, thus, to eradicate tuberculosis. Evidence from high- burden communities suggests that this is possible. Tuberculosis, theoretically, is a disease that should be able to be eradicated but this well require new tools to accomplish.

Present study was conducted to study the disease pattern in BCG immunized children aged between 2 months- 12 years.

\section{MATERIAL AND METHODS}

This prospective study was conducted in the Department of Pediatrics Navodaya Medical College Hospital and Research Centre, Raichur, Karnataka from November 2009 to October 2010. Children in the age group from 2 months to 12 years attending the Outpatient Department, admitted in the wards or in the PICU with sysmptoms suggestive of Tuberculous disease were subjected for detailed evaluation. Asymptomatic children close contact with adult Tuberculous patients were also investigated and included in the study if found to have Tuberculous disease.
All had BCG vaccination and the presence of BCG scar were included in this study.

Inclusion criteria: 1. Children with Recurrent or prolonged fever, Recurrent respiratory infections and Recurrent wheezing 2. Children with Poor weight gain 3. Children with any of the symptoms /signs like Lymphadenopathy, Hepato splenomegaly, Meningitis, Convulsions and Serous effusions 4. Babies not thriving well

Exclusion criteria: 1. Asymptomatic Mantoux positive children with no evidence of disease 2. Babies less than 2 months of age 3.Children with BCG adenitis 4. Children those without BCG vaccination or Scar 5.children on empirical anti-tubercular drugs were excluded from the study.

Study was approved by ethical committee of the institute. A valid written consent was taken from parents of children after explaining study to them.

The diagnostic criteria for Tuberculous disease were 1.Positive Mantoux reaction along with chest skiagram finding 2.In Mantoux test negative clinically suspected patients, demonstration of acid fast bacilli in gastric aspirate 3. Lymph node biopsy revealing Tuberculous pathology or 4. CSF picture suggestive of Tubercular meningitis 5. CT scan appearance characteristic of tuberculoma brain were considered as diagnostic criteria.

Data was collected with pre tested questionnaire. Data included sociodemographic data, clinical history and clinical examination. In the history details regarding familial and extra familial contact with TB was enquired apart from the details of the ill-ness.

Socioeconomic status was assessed by modified method of Kuppuswami100. Nutritional assessment was done according to IAP classification 101 .

Mantoux test was done with $0.1 \mathrm{ml}$ of PPD (5TU PPD-S) injected on volar surface of forearm for all patients and induration exceeding $10 \mathrm{~mm}$ after $48-72$ hours was considered as positive reaction102-106.

$\mathrm{X}$-ray chest, hemogram and urine routine examination were done for all patients. Radiologic findings were analyzed with the help of a competent radiologist in the institution.

In relevant cases gastric aspirate for AFB smear examination for three consecutive days. Lymph node biopsy, cerebrospinal, pleural and peritoneal fluid studies including adenosine deaminase test were done.

Other diagnostic possibilities were excluded by appropriate investigation. Confirmed cases were treated according to IAP Consensus on Treatment of Childhood TB. Patients were followed up at monthly intervals. During each visit they were clinically assessed for nutritional status, clinical improvement and evidence of any drug toxicity. All the family members with symptoms were screened with chest $\mathrm{X}$-ray to exclude intra familial contact. 
Siblings of index cases were screened with Mantoux test and chest X-ray to exclude asymptomatic Tuberculous disease.

\section{RESULTS}

In our study, 159 children who fulfilled the diagnostic criteria for Tuberculous disease were initially included in the study but final analysis was done in only 104 patients who could be completely followed up. In our study, maximum number of cases were in the 1 to 5 years age group $43(41.34 \%)$, $29(27.88 \%)$ were in 6 to 10 years age group, $18(17.34 \%)$ were under 1 year and $14(13.46 \% 0$ were in the age group 11 to 12 years. In this study Male female ratio was nearly equal to 1.03:1. Table 1 shows that most common type of tuberculosis was primary pulmonary complex occurring alone $(50.96 \%)$ or in combination with other lesions $(78.84 \%)$. Of this, $9(8.65 \%)$ had progressive primary disease. $2(1.92 \%)$ had disseminated tuberculosis, $5(4.80 \%)$ had military TB; $13(2.88 \%)$ cases had lymph node associated with primary complex $9(8.65 \%)$. One case of congenital tuberculosis aged 2 months and 7 days which presented with respiratory distress and hepatosplenomegaly.(table 1). Out of total 53 cases of PPC maximum number of cases were seen in children aged 1-5 years ( 16 cases) and 6-10 years ( 15 cases). Tuberculoma was found to be more in children aged between 6-10 years (5 cases). Lymph node TB associated with PPC was found to be more in children aged between 1-5 years (5 cases). (table 2 ). Most of the cases 60(57.6\%) belonged to low SES, 37(35.5\%) to middle SES and $7(6.7 \%)$ to High socio-economic status. In our study, 23(22.11\%) cases revealed positive history of contact with adult case of tuberculosis. Screening the family members disclosed two new cases. Screening the sibling of index cases identified three new cases of pulmonary tuberculosis. Fig 1 shows predominant symptoms of presentation are Fever $68(65.38 \%)$ and cough 61 (58.65\%). $38(36.53 \%)$ had initial presentation as seizures. One third had weight loss or poor weight gain, significant lymphadenopathy was observed in $28(26.92 \%)$ cases and $14(13.46 \%)$ had wheezing. Three patients were investigated because of positive contact history and had primary pulmonary complex. Table 3 shows 32 cases of PPC had normal nutrition and 10 cases had Grade II malnutrition. 6 cases with normal nutritional status were diagnosed with Tuberculoma. Disseminated and Milliary TB were more in children with Grade III and Grade IV malnutrition (2 cases each in Grade IV). 4 cases of TBM had normal nutrition whereas 3 cases each had grade I and grade III malnutrition. 2 cases of abdominal tuberculosis had normal nutrition and 1 case had grade I malnutrition. 4 cases of lymphnode tuberculosis with PPC had grade III malnutrition and 3 had normal nutrition. Out of the total 104 cases 44 cases $(42.30 \%)$ did not have anemia. 26 cases $(25 \%)$ had mild anemia,22 cases(21.15\%) had moderate anemia whereas 12 cases $(11.53 \%)$ had severe anemia. In our study, abnormal chest X-ray was seen in 92 cases. The commonest radiological abnormality was parenchymal lesion 67(64.42\%), hilar adenopathy $18(17.30 \%)$ and parenchymal plus nodal lesion $7(6.73 \% 0$. The other patients without any skiagram changes had gland TB proved by FNAC. In our study, $60(57.69 \%)$ patients had positive tuberculin test. Out of the remaining tuberculin negative cases $13(12.5 \%)$ cases of TBM diagnosed with CSF examination, $12(11.53 \%)$ had Tuberculoma diagnosed by CT brain and $4(3.84 \%)$ had lymphnode tuberculosis diagnosed by FNAC. Gastric aspirate for AFB was not found, while in 92 cases had positive radiological signs of tuberculosis.

Table 1: Distribution of patients according to types of tuberculosis

\begin{tabular}{ccc}
\hline Types of tuberculosis & No. of Patients & Percentage \\
\hline Primary pulmonary complex (PPC)+PPD & 53 & 50.96 \\
Lymph node tuberculosis & 6 & 05.76 \\
Disseminated TB & 2 & 01.92 \\
Military TB & 5 & 04.80 \\
TBM & 13 & 12.5 \\
Tuberculoma & 12 & 11.53 \\
Peritoneal TB & 3 & 02.88 \\
Lymph node TB associated with PPC & 9 & 08.65 \\
Congenital tuberculosis & 1 & 00.96 \\
Total & 104 & 100.00 \\
\hline
\end{tabular}

Table 2: Distribution of patients according to types of tuberculosis and age group

\begin{tabular}{ccccc}
\hline Types of TB & $<1$ Year & 1-5 Years & 6-10 Years & 11-12 Years \\
\hline PPC & 12 & 16 & 15 & 10 \\
LN & 2 & 1 & 1 & 2 \\
Diss.TB & 1 & - & 1 & - \\
Mill.TB & - & 5 & - & - \\
TBM & 4 & 5 & 3 & 1 \\
Tuberculoma & - & 3 & 5 & 4 \\
Abd.TB & 1 & - & 2 & - \\
PPC+LN & 1 & 5 & 3 & - \\
Cong.TB & 1 & - & - & - \\
\hline
\end{tabular}




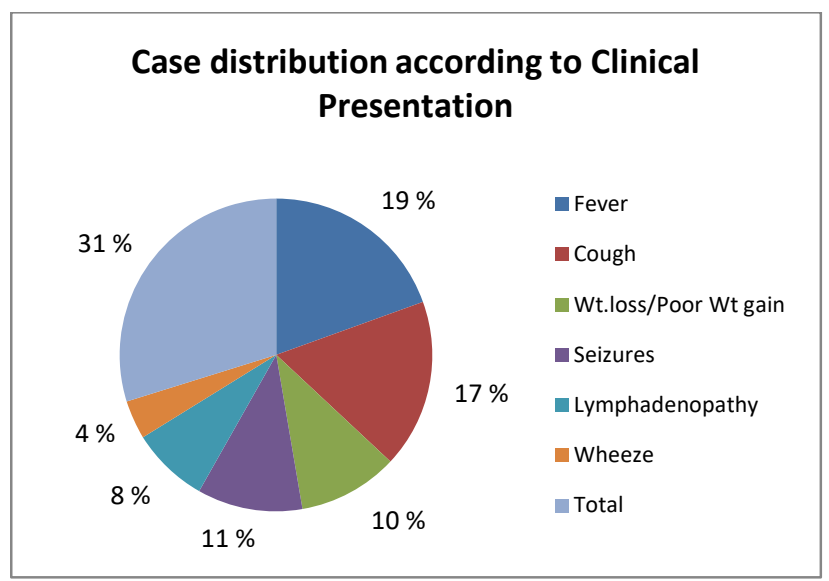

Figure 1: Distribution of patients according to types of tuberculosis and clinical presentation

Table 3: Distribution of patients according to types of tuberculosis and nutritional grade

\begin{tabular}{cccccc}
\hline Types of TB & Normal & Grade I & Grade II & Grade III & Grade IV \\
\hline PPC & 32 & 9 & 10 & 1 & 1 \\
LN & 1 & 3 & 1 & 1 & - \\
Diss.TB & - & - & - & - & 2 \\
Mill.TB & - & 1 & 1 & 1 & 2 \\
TBM & 4 & 3 & 2 & 3 & 1 \\
Tuberculoma & 6 & 4 & 1 & 1 & - \\
Abd.TB & 2 & 1 & - & - & - \\
PPC+LN & 3 & 1 & 1 & 4 & - \\
Cong.TB & 1 & - & - & - & - \\
\hline
\end{tabular}

\section{DISCUSSION}

Age incidence in our series was $62(62.5 \%)$ in 2 months to 6 years and $42(40.38 \%)$ in 6-12 years. Ramachandran et al reported $89.8 \%$ below 6 years and $9.12 \%$ between $6-12$ years. ${ }^{10}$ Bhakku et al reported $71 \%$ under 5 years of age and $22.9 \%$ in $5-12$ years. ${ }^{11}$ Our incidence correlates well with various studies.

Udani in his study on 2000 BCG vaccinated children with tuberculosis has observed that $91 \%$ has intrathoracic lesions with majority having mediastinal lymph node tuberculosis. ${ }^{12}$ The incidence of neurotuberculosis and other type of disseminated tuberculosis were $45 \%$ each in his study with modified clinical pictures of neuro tuberculosis, serous Tuberculous meningitis and localized Tuberculous disease in meninges and brain. ${ }^{13}$ Isolated splenomegaly, hepato-megaly, single organ involvement, bone and joint tuberculosis were also high. ${ }^{14}$ Mathur et al. in a comparative study between BCG vaccinated and non vaccinated groups of patients could not find any significant difference in clinical pattern or mortality rate. ${ }^{8}$

In this study, $24.4 \%$ has thoracic $\mathrm{TB}, 68.6 \%$ had TB meningitis and mortality rate was $27 \%$ in $B C G$ vaccinated group. The clinical pattern in relation with nutritional status and socioeconomic conditions were not analyzed in these studies.
In the present study, $78.84 \%$ had intra-thoracic lesions alone, $33.65 \%$ had disseminated $\mathrm{TB}, 5.76 \%$ had isolated lymph node TB and Nearly $1 \%$ had hypersensitivity phenomena. Mediastinal lymph node TB, modified neuro TB and other forms of TB described by Udani were not observed. A control study to compare the percentage of different forms of TB in BCG non vaccinated group was not studied.

All cases of disseminated TB in our study were seen in children with PEM and in those belonging to low socio economic group. Various studies reveal the association between low socio-economic status and severe forms of TB. ${ }^{15,16}$ The impact of under nutrition on childhood tuberculosis progressing to severe and disseminated forms was not evaluated in these series whereas in the present study, 58(55.76\%) had protein energy malnutrition (PEM). Out of 104 case $60(57.69 \%)$ tested positive for tuberculin test,92 cases $(88.46 \%)$ had X-ray changes. 12 cases had radiological features in CT brain. Gastric aspirate for AFB was negative in our study. Abnormal chest X-ray was seen in 92 cases. The commonest radiological abnormality was parenchymal lesion 67(64.42\%), hilar adenopathy $18(17.30 \%)$ and parenchymal plus nodal lesion $7(6.73 \% 0$. The other patients without any skiagram changes had gland TB proved by FNAC. 46 (44.23\%) case of PPC did not have significant history of contact whereas $7(6.73 \%)$ cases 
of PPC had a history of contact. $12(11.53 \%)$ cases of tuberculoma revealed negative history of tuberculosis. 12 cases of PPC developed respiratory distress as a complication and 10 cases of PPC later developed pleural effusion. 2 cases of TBM developed hydrocephalus as a complication. 1 case of abdominal tuberculosis developed perotinitis as a complication of the disease. 3 cases of lymphnode tuberculosis with PPC developed respiratory distress and 1 case developed pleural effusion.

It is stated that BCG vaccine has protective value against dissemination of tuberculosis because $\mathrm{T}$ cells in vaccinated children are highly sensitized preventing hematogenous spread. ${ }^{12}$ In under-nourished children, cell mediated immunity is greatly impaired and hence the vaccine fails in preventing dissemination of tuberculosis. The ICMR BCG trials in Chingleput also report that BCG offers no protection against primary tubercular infection or its progression to severe forms. ${ }^{17}$ Presently, BCG vaccination is advised to be continued in infants and children to reduce the risk of primary tubercular infection disseminating to severe forms. ${ }^{18}$

\section{CONCLUSION}

Tuberculosis in children mainly presents as Fever $68(65.38 \%)$ and cough $61(58.65 \%)$ initial presentation as seizures $38(36.53 \%)$.

\section{REFERENCES}

1. Global tuberculosis control; surveillance, planning, financing. WHO report 2006. Geneva: World Health Organization, 2006. (WHO/HTM/TB2006.362) (http://www.who.int/th/publications/global report/2006/pdf/full_report.pdf).

2. Editorial - tuberculosis in the Third World: Thorax 1991, 46: 689-91.

3. India TB. 2006 RNTCP status report. New Delhi, India: Central TB Family Welfare, 2000 (Accessed september1, 2007, at http://www.tbcindia.org.)
4. Chauhan LS, Arora VK. Management of Pediatric Tuberulosis Under the Revised National Tubercuosis Control Programme. India J Pediatr 2004; 71: 341-343.

5. Grahm SM, Daley HM, Banerjee A, Salaniponi FM, Harries AD. Ethambutol in Tuberculosis. Time to reconsider? Arch Dis Child 1988; 79: 274-278.

6. Bharadwaj AK, Bharadwaj PK, Gupta BP, Swami NM, Ahluwalia SK, Vaidya NK, Factors influencing immunization status of urban and rural children in Delhi, Indian J Med Res 1990; 15: 150-184.

7. Tuberculosis Prevention Trial, Madras. Trial of BCG vaccine in South India for tuberculosis prevention. Indian J Med Res 1980; 72 (suppl): 1 - 70.

8. Mathur GP, Mathur S, Gupa V, Bhalla M, Bhalla JN, Tripathi VN et al. tuberculosis in children with reference to their immunization status: a hospital bases study. Indian Pediatri 1990; 28: 569 - 570.

9. Steinbrook R. Tubewrculosis and HIV in India. N Engl J Med 2007; 365: 1198 - 1199.

10. Bhaku O.N, Gupta S.N - tuberculosis in children. Ind. J. Ped 36:254, 1969.

11. Ramachandran R.S, Purnayam -Tuberculosis in children Ind.. Ped. 3:216, 1966

12. Udani PM. BDg vaccination in India and tuberculosis in children, Indian J.Pdiatr 1994: 61: 451 - 462.

13. Udani PM. BCG vaccination and child neurology from modern perspectives of child neurology. In: Proceedings of the Joint Convention of the 5th International Congreess and 3rd Asian and Oceanian Congress of Child Neurology. Tokyo No 4-9, 1990 Jap Ped Neurol Soc 1991; 14:

14. Vitalani N, Udani PM. A study of 292 autopsy proved cases of tuberculosis. Indian J Tub 1982; 39: 95 - 97.

15. Magoatr ML, Andurkar GP, Katira OP. Primary Pulmonary tuberculosis in children. Indian pediatr 1974; 11: $529-523$.

16. Shah RH. Ramakrishna B, Mehta DK, Shah RC, Pulmonary tuberculosis in Ahmedabar Epidemiology, diagnosis and short course chemethorapy. Indian J Pediatr 1992; 59: 435 - 442 .

17. Tuberculosis Research Center (ICMR) Chennai. Fifteen years follow up of trial of BCG vaccine in South India for tuberculosis prevention. Indian J Med Res 1992; 110: 56 59.

18. John TJ. Tuberculosis control, without protection from BCG. Indian Pediatr 2000; 37: 9-18.

\section{Source of Support: None Declared Conflict of Interest: None Declared}

Policy for Articles with Open Access:

Authors who publish with MedPulse International Journal of Pediatrics (Print ISSN: 2579-0897) (Online ISSN: 2636-4662) agree to the following terms: Authors retain copyright and grant the journal right of first publication with the work simultaneously licensed under a Creative Commons Attribution License that allows others to share the work with an acknowledgement of the work's authorship and initial publication in this journal.

Authors are permitted and encouraged to post links to their work online (e.g., in institutional repositories or on their website) prior to and during the submission process, as it can lead to productive exchanges, as well as earlier and greater citation of published work. 